\title{
Use of social media networks in learning and its impact on students' academic skills: Case study of the computer science college at UOH
}

\author{
Sondess Ben Aoun ${ }^{1, *}$, Houssem Jerbi ${ }^{2}$ \\ ${ }^{1}$ College of Computer Science and Engineering, University of Hail, Hail, Saudi Arabia \\ ${ }^{2}$ College of Engineering, University of Hail, Hail, Saudi Arabia
}

\section{A R T I C L E I N F O}

\section{Article history:}

Received 5 March 2017

Received in revised form

14 June 2017

Accepted 15 June 2017

\section{Keywords:}

Social media networks

Learning techniques

Impact

Educational purposes

Statistics

Analysis

\begin{abstract}
A B S T R A C T
As social media networks (SMN) have witnessed an explosive popularity, one can affirm that technology is a vital part in today's student success. This is equally true at the academic and personal levels. In this presentation, we explore the use of the emerging SMN in students' learning at the College of Computer Science and Engineering (CCSE-female branch) at the University of Hail (UOH) in Saudi Arabia. We pose and try to answer the following questions: Are SMN pedagogically beneficial or harmful? Does the adoption of SMN by students have an effective role in enhancing academic levels? In what follows, we will examine how students use social media sites to learn. We will also study the academic impact of SMN. This s will allow us to develop and improve the usage of SMN for educational purposes and suggest various methodological approaches which can be used by university students. Furthermore we will present new methods and advanced online electronic surveys and statistics based on I-Clouding applications to measure the awareness of SMN's, frequency of use according to the simplicity and rapidity students of SMN in learning and getting information, the influence of SMN usage on their academic performance, and their effectiveness in time and diffusion of information.
\end{abstract}

(C) 2017 The Authors. Published by IASE. This is an open access article under the CC BY-NC-ND license (http://creativecommons.org/licenses/by-nc-nd/4.0/).

\section{Introduction}

Education systems and styles have developed rapidly in the last decades. Traditional approaches and methods of learning are affected by technological invention and started to vanish as many researchers have demonstrated ( $\mathrm{Lu}$ and Churchill, 2014). Nowadays, there is an explosive growth in the number and use of social media networks in the entire world. For the past several years, UOH has been researching faculty and students' use of technology in teaching and learning in an effort to emphasizes the effective use of technology, the opportunities they offer to students (Hussein, 2016). As an implementation of our commitment to sharing our knowledge with the higher education community especially $\mathrm{UOH}$, this statistical research contains the analysis and the result of our recent survey entitled: "The Use of Social Media Network in Learning Based on Real Statistics Conducted at the College of Computer

\footnotetext{
* Corresponding Author

Email Address: s.benaoun@uoh.edu.sa (S. B. Aoun) https://doi.org/10.21833/ijaas.2017.08.022

2313-626X/C 2017 The Authors. Published by IASE. This is an open access article under the CC BY-NC-ND license (http://creativecommons.org/licenses/by-nc-nd/4.0/)
}

Science Students at University of Hail." Recent researches Studies demonstrate that social media networks can be a useful tool when used carefully instead of a distraction especially in learning (Inan et al., 2010). Using social media not only brings current technology to the students, but it also helps bridge the digital divide among lower-income students (Moran et al., 2011). These students may not have the constant access to social media that their counterparts do. Why should they be left behind as technology continues to march forward?

Social media is an ingrained part of today's society, is a medium that is by its very nature non centralized, meaning that in both form and content, it is user created, user controlled, flexible, democratic, and both very transparent and very not so. The most distinctive aspect of social media networks is their potential to transform from a way of pushing content outward to a way of inviting conversation, of exchanging information, and of invoking unparalleled individual, industry, societal, and even global change (Gerlich et al., 2011). Our advanced electronic survey based on i-clouding tool: Evalandgo, included Facebook, WhatsApp, YouTube, LinkedIn, Slideshare social media sites use.

To discover exactly how university students use social media sites in learning at the College of CSE 
(female side), we asked survey participants to mention if they are fully aware of these social media sites and if they are using them in learning; about their frequency of use according to the simplicity and rapidity of these social networks in learning and about getting information and their effectiveness in time and emergence of information.

The objective of this study is to examine impacts of students social media use in learning on their skills improvement and to suggest various methodological approaches which can be used at the university by the students to develop and improve more the usage of SMN for educational purposes.

In this research paper students' levels of awareness of the various social media sites is measured to determine if students are knowledgeable about the existence of the various social media sites as well as the impact of their use in learning purpose on students' academic level is performed. Their opinions concerning the most used SMN in learning, the easiest and the simplest and the faster in information diffusion will be studied, and the role of social media in saving effort and getting information in learning is determined.

The research findings and recommendations could be adopted and implemented to benefit the area of teaching and learning at CSSE and the University of Hail at large.

\section{Surveys results and analysis}

Advanced online survey software tool is used in this study which contains eight questions. It is based on I-clouding application that provides users with tools to create their electronic surveys and then generates an on line URL link to be sent for all concerned people. In this study students of Computer Sciences and Engineering College are concerned.

The most powerful use of such advanced tool in creating and generating the electronic survey, is the rapidity of sending this survey for all the students and this by copying and posting the generated link by the software via WhatsApp and via their emails (Williams, 2013).

As shown in Figs. 1 and 2, near to one hundred students respond to the survey questions in four days with a very quick rate of responding. Fig. 3 shows that the majority of students $(97 \%)$ respond to all the pages of the survey and this is due to its simplicity and ease of use.

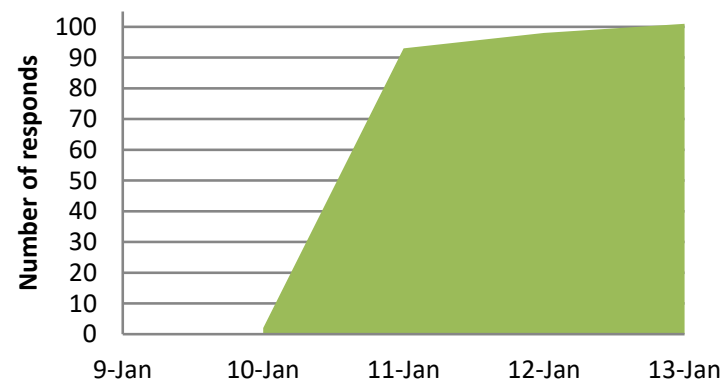

Fig. 1: Number of students' responses

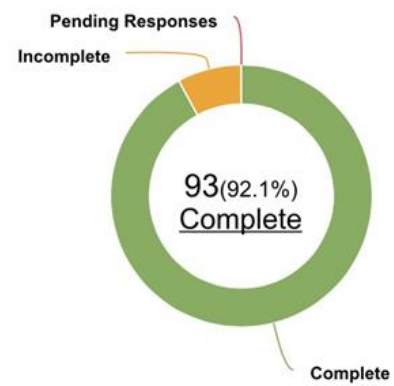

Fig. 2: Rate of survey students' responses

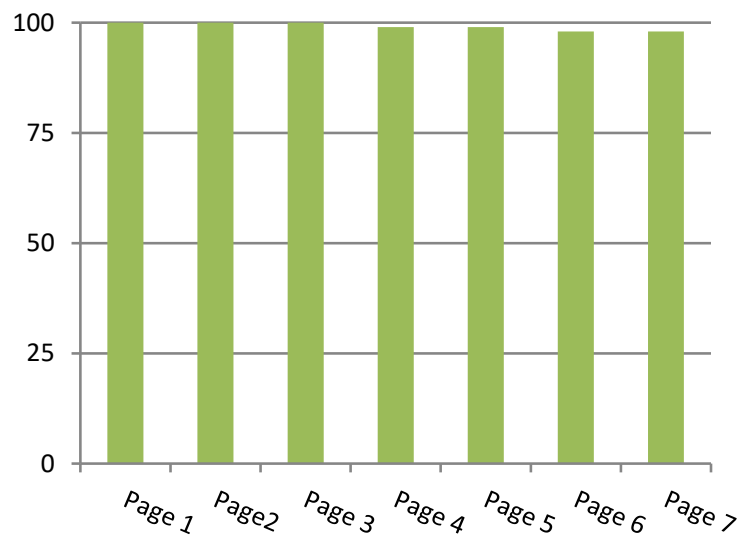

Fig. 3: Details of students' responses per page

\subsection{CCSE students' awareness of SMN}

The first aspect to be examined is the level of students' awareness of a number of popular social media sites. As might be expected given the high level of awareness of social media among the general population, university students are very familiar with social media knowing that $97 \%$ of them are possessing smart phones as demonstrated in Fig. 4 and Table 1, and as it's shown in Fig. 5 and Table 2 over $70 \%$ report that they are aware more of WhatsApp. The awareness level drops for other sites, with over $17 \%$ saying that they know of YouTube, 9\% for Facebook.

Table 1: CCSE students' awareness of SMN

\begin{tabular}{ccc}
\hline Question & Students No. & Percentage (\%) \\
\hline Did you have a smart phone? & 98 & 100 \\
Yes & 96 & 97.96 \\
No & 2 & 2.04 \\
\hline
\end{tabular}

Table 2: CCSE students favourite social media sites used in learning

\begin{tabular}{ccc}
\hline Question & Students No. & $\begin{array}{c}\text { Percentage } \\
(\%)\end{array}$ \\
\hline $\begin{array}{c}\text { Which of the following SMN are } \\
\text { you more aware about? }\end{array}$ & 94 & 100 \\
Facebook & 9 & 9.57 \\
WhatsApp & 66 & 70.21 \\
YouTube & 16 & 17.02 \\
LinkedIn & 2 & 2.13 \\
SlideShare & 1 & 1.06 \\
\hline
\end{tabular}

Once you get past the most common of the social media sites, however, the level of awareness drops considerably. While over $70 \%$ of students are aware of at least one of the five social media sites, less than $2 \%$ report they are aware of presentation sharing 
site Slideshare and LinkedIn social network. It's safe to say that students have high levels of awareness of WhatsApp which is known as a place to post all things that student's likely use in their classes anyway and most of them create groups for each class, on which they can be aware about all the news: posted assignments, announcements, important deadlines.

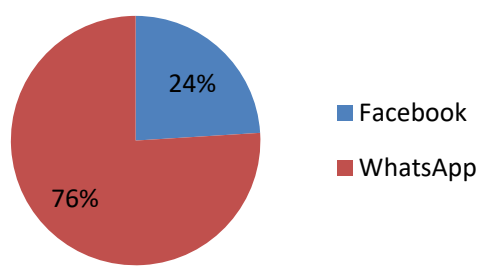

Fig. 4: Percentage of students' smart phones possessing

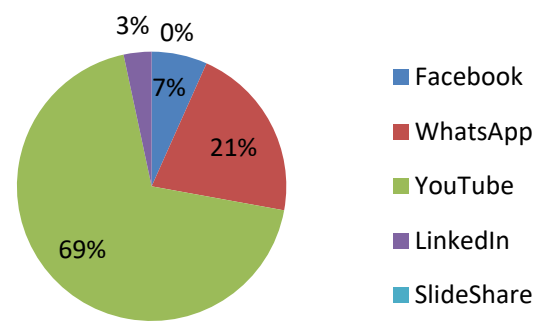

Fig. 5: Percentage of students' awareness of SMN

In the two last years, WhatsApp has become the most popular social media used among all others sites not only by students but by all users of SMN known by its rapidity of information emergency and simple use of posting and conversation (Jimoyiannis et al., 2013).

\subsection{CCSE students favourite social media sites used in learning}

Fig. 6 demonstrates that $67 \%$ CCSSE students prefer using YouTube in their online learning (Table 3). This is very logical as YouTube is an excellent self-learning tool for students and they can watch lectures and resources before entering to the classroom or learning new topics by themselves. It increases their understanding especially when they have difficulties in lectures and even in practice sessions. Also, students can create their own videos instead of watching material created by others like blogging, This is because the material will be seen by a wider audience, students will be more apt to do their very best in creating a video, and they will enjoy being able to express their creativity as they connect more deeply with course material.

WhatsApp is used by $20 \%$ of students in learning; this drop in use comparing with YouTube is due to the fact that WhatsApp is used more in fast communication, posting announcements, and students/teachers interactions. On the other hand Slideshare and LinkedIn social networks are somewhat not used by students. In fact, only $3 \%$ use both which is rather normal result as students are not aware of these sites as it was demonstrated in previous analysis, but many researches prove that using such learning tools increases student academic performance especially Slideshare, as they can download any needed documents easily (Barhoumi, 2015).

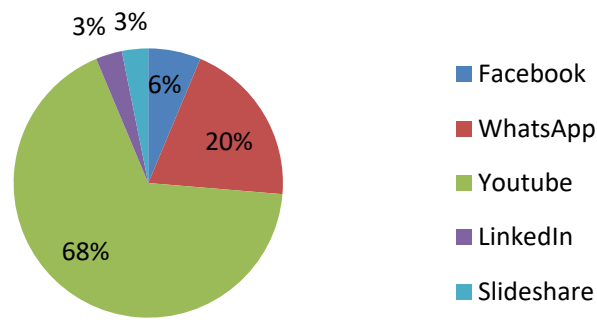

Fig. 6: Percentage of favourite SMN used by students in learning

\subsection{The easier and simplest SMN more used by students in learning}

Since determining how social media can be of an effective use in education, it is important to identify what is the most used social media by students. With such information it is possible to create an effective learning method where majority of students of students can participate.

According to $70 \%$ students' opinions YouTube is the easiest and simplest social media network used in learning as mentioned in the statistics in Fig. 7 and this is very true because using YouTube for learning purpose doesn't need a lot of effort since YouTube is easily accessed and students can attend any lesson by simple search related to any field or subject (Table 4).

Table 3: CCSE students favourite social media sites used in learning

\begin{tabular}{ccc}
\hline Question & Students No. & $\begin{array}{c}\text { Percentage } \\
(\%)\end{array}$ \\
\hline $\begin{array}{c}\text { Which of the following SMN are } \\
\text { you more aware about? }\end{array}$ & 95 & 100 \\
Facebook & 6 & 6.32 \\
WhatsApp & 19 & 20 \\
YouTube & 64 & 67.37 \\
LinkedIn & 3 & 3.16 \\
SlideShare & 3 & 3.16 \\
\hline
\end{tabular}

Table 4: The easier and simplest SMN more used by students in learning

\begin{tabular}{|c|c|c|}
\hline Question & $\begin{array}{c}\text { Students } \\
\text { No. }\end{array}$ & $\begin{array}{c}\text { Percentage } \\
(\%)\end{array}$ \\
\hline $\begin{array}{l}\text { Which of the following SMN you } \\
\text { feel easier and faster to use in } \\
\text { learning? }\end{array}$ & 94 & 100 \\
\hline Facebook & 4 & 4.26 \\
\hline WhatsApp & 20 & 21.28 \\
\hline YouTube & 66 & 70.21 \\
\hline LinkedIn & 1 & 1.06 \\
\hline SlideShare & 3 & 3.19 \\
\hline
\end{tabular}

$22 \%$ of them say that WhatsApp is simple and easy in use. This percentage is accepted because WhatsApp is considered as a social media site known 
for its easy way of posting and accessing when compared with LinkedIn and Slideshare (Cheung et al., 2008).

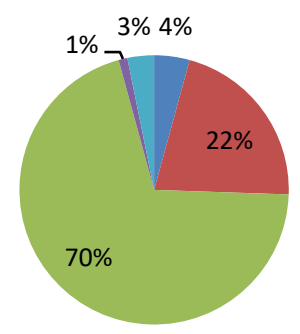

Facebook
WhatsApp
Youtube
- LinkedIn
Slideshare

Fig. 7: Percentage of easier and simplest SMN used by students in learning

\subsection{Impact of Social media networks use in learning on students' educational level}

In this section more than $90 \%$ of students consider that using social media networks in learning has a positive impact on their level of knowledge and a positive effect on their academic performance as Fig. 8 demonstrates (Table 5).

So most of CSSE students believe that social media can be used effectively learning purposes. These tools encourage students to interact with others by posting their favourite quotes or facts from a particular lesson, have them interact with their teachers by posting questions or comments, can understand more their lectures and it was evident that College of CSSE students have many information technology based course such as multimedia and web technology, software technology and network technology, so the use of SMN in learning is in a higher percentage than other students. Because of their course structure these students work with Social media and online tools more than others.

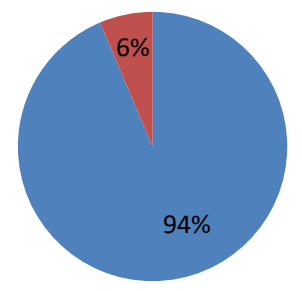

- Yes

$\square$ No

Fig. 8: Percentage of the effect of SMN use on students' academic performance

\subsection{Role of social media in saving effort and getting information in learning}

According to the research sample in Fig. 9, 99\% of students agree that the use of SMN in learning save their efforts in getting information in learning (Table 6). This depicts that the majority of students use considerably time on social networks. This time can be converted to a valuable learning experience through the help of social media.

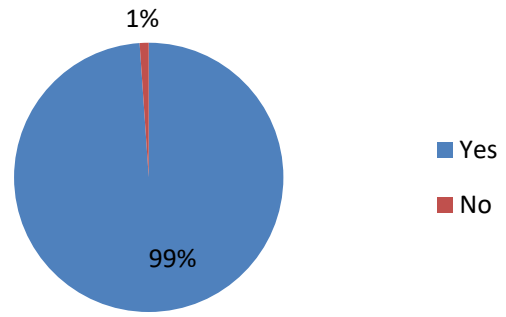

Fig. 9: Percentage of the Role of social media in saving effort and getting information.

2.6. Social media sites effectiveness use in announcements and fixing assessments and homework submission deadline compared with blackboard

When asked about the Social media sites effectiveness use in announcements and fixing assessments and homework submission deadline compared with e-learning tools the overwhelming majority (78\%) of students agree with the use of social media sites as shown in Fig. 10 and Table 7, with just $22 \%$ of students disagreeing with the statement, this is a logic result if we consider that most of e-learning tools (Blackboard for example) used for posting announcements takes more time and need from students to be logged in, however WhatsApp for example offers a quick way to post class announcements and reminders as well as realtime information. Social media network efficiency and their students use in information diffusion.

Table 5: Impact of Social media networks use in learning

\begin{tabular}{ccc}
\multicolumn{3}{c}{ on students' educational level } \\
\hline Question & $\begin{array}{c}\text { Students } \\
\text { No. }\end{array}$ & $\begin{array}{c}\text { Percentage } \\
(\%)\end{array}$ \\
\hline $\begin{array}{c}\text { According to you, did the SMN use } \\
\text { in learning improve the students' }\end{array}$ & 94 & 100 \\
$\begin{array}{c}\text { academic level? } \\
\text { Yes }\end{array}$ & 88 & 93.62 \\
No & 6 & 6.38 \\
\hline
\end{tabular}

Table 6: Role of social media in saving effort and getting information in learning

\begin{tabular}{ccc}
\multicolumn{3}{c}{ information in learning } \\
\hline Question & $\begin{array}{c}\text { Students } \\
\text { No. }\end{array}$ & $\begin{array}{c}\text { Percentage } \\
(\%)\end{array}$ \\
\hline $\begin{array}{c}\text { Did you think that the use of } \\
\text { SMN provides a gain of effort } \\
\text { and time in learning }\end{array}$ & 93 & 100 \\
Yes & 92 & 98.92 \\
No & 1 & 1.08 \\
\hline
\end{tabular}

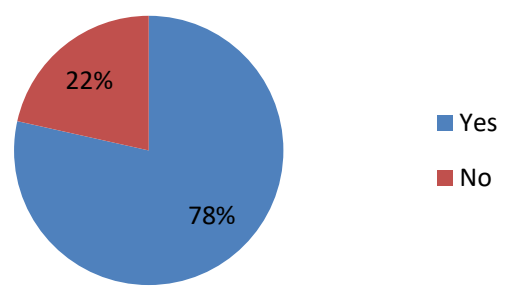

Fig. 10: Percentage of social media networks use in announcements and fixing assessments compared with e Blackboard 


\subsection{Social media network efficiency on students use in information diffusion}

When asked about their opinions concerning the most used social media network in information dissemination, the majority of their responses go for WhatsApp (60\%), 25\% of them think that YouTube is faster in diffusing information as shown in Fig. 11 and Table 8. The percentage of diffusing the information through Facebook is just for $8 \%$ and $4.5 \%$ for LinkedIn and $2.2 \%$ for Slideshare. This statistic is true especially for WhatsApp, this social media site is very efficient even for teacher and students to diffuse the information because it is easy, simple and can be used anywhere and anytime.

Table 7: Social media sites effectiveness use in announcements and fixing assessments and homework submission deadline compared with e-learning tools

\begin{tabular}{ccc}
\hline Question & Students No. & Percentage (\%) \\
\hline Did the use of SMN in announcements and fixing assessments & 93 & 100 \\
dates and delivery duties are more efficient than Blackboard? & 73 & 98.92 \\
Yes & 20 & 1.08 \\
\hline No &
\end{tabular}

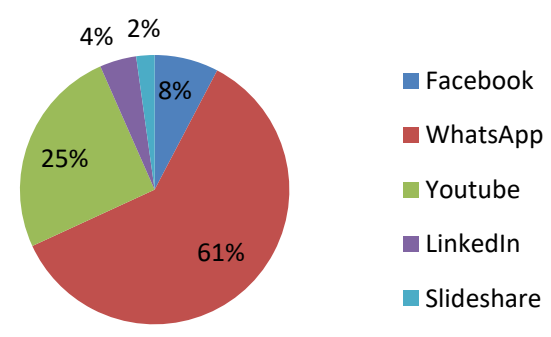

Fig. 11: Percentage of most used social media networks used in information diffusion

For instance, for a class discussing a current event or topic such as career ideas, WhatsApp can provide up-to-date information easily, and students can learn more about what is happening in the world around them. They can use this information in a variety of class discussions, research, and writing projects (Martin, 2008).

\section{Conclusion}

Such field of research is important not least because since social media networks is a phenomenon which is going to grow at a fast pace. It is therefore important to understand the effects it has on university student's use, especially in learning. As the statistics show in this study: more than $90 \%$ of CSSE students use social media networks in learning. Most of them use YouTube and WhatsApp due to their simplicity, rapidity of use, and abundance of learning sources. However, we have noticed that students are not aware of two powerful social media sites: LinkedIn and Slideshare. The latter make it easier for users to share slides, lectures, books covering all topics that are useful for students. Primary recommendation is usage of Social Media Networks for educational purposes should be improved within CSE College. There can be various methodological approaches which can be used to encourage students to use Slideshare in their researches. These includes: study groups, communities, and forums. If real time learning experience such as online discussions is proposed the ideal time would be evening to night because many students are free to use social media at these two time slots. We should encourage online learning and teaching activities as university students have regular access to the internet through their own computers, laptops or smart phones. It is evident that WhatsApp is the most used and popular social network among students.

Table 8: Social media network efficiency on students use in information diffusion

\begin{tabular}{|c|c|c|}
\hline Question & $\begin{array}{l}\text { Students } \\
\text { No. }\end{array}$ & $\begin{array}{c}\text { Percentage } \\
(\%)\end{array}$ \\
\hline $\begin{array}{c}\text { Which of the following SMN you } \\
\text { feel faster in learning } \\
\text { information diffusion? }\end{array}$ & 91 & 100 \\
\hline Facebook & 7 & 7.69 \\
\hline WhatsApp & 55 & 60.44 \\
\hline YouTube & 23 & 25.27 \\
\hline LinkedIn & 4 & 4.4 \\
\hline SlideShare & 2 & 2.2 \\
\hline
\end{tabular}

Accordingly, more activities based on WhatsApp media should be encouraged since it will enhance students' participation. Students and academic staff must learn how to use Social network Technologies effectively. This can be achieved by organizing seminars and workshops on the utilization of these networks. The university should also appoint a committee to assess the progress of the use of the technology. Likewise, materials can be shared through social media and panels.

\section{References}

Barhoumi C (2015). The effectiveness of WhatsApp mobile learning activities guided by activity theory on students' knowledge management. Contemporary Educational Technology, 6(3): 221-238.

Cheung WS, Hew KF, and Ng SL (2008). Toward an understanding of why students contribute in asynchronous online discussions. Journal of Educational Computing Research, 38(1): 29-50.

Gerlich RN, Browning L, and Westermann L (2011). The social media affinity scale: Implications for education. Contemporary Issues in Education Research, 3(11): 35-42.

Hussein ET (2016). The effectiveness of using blackboard in improving the English listening and speaking skills of the female students at the University of Hail. Advances in Social Sciences Research Journal, 3(12): 81-93.

Inan FA, Flores R, and Grant MM (2010). Perspectives on the design and evaluation of adaptive web based learning 
environments. Contemporary Educational Technology, 1(2): 148-159.

Jimoyiannis A, Tsiotakis P, Roussinos D, and Siorenta A (2013). Preparing teachers to integrate mobile in school practice: Toward a framework for Pedagogy 2.0. Australasian Journal of Educational Technology, 29(2): 248-267.

Lu J and Churchill D (2014). Using social networking environments to support collaborative learning in a Chinese university class: Interaction pattern and influencing factors. Australasian Journal of Educational Technology, 30(4): 472486.
Martin F (2008). Blackboard as the learning management system of a computer literacy course. Journal of Online Learning and Teaching, 4(2): 138-145.

Moran M, Seaman J, and Tinti-Kane H (2011). Teaching, learning, and sharing: How today's higher education faculty use social media. Babson Survey Research Group, Babson College, USA. Available online at: http://files.eric.ed.gov/fulltext/ED535130 .pdf

Williams PE (2013). Roles and competencies for distance education programs in higher education Institutions. The American Journal of Distance Education, 17(1): 45-57. 